\title{
Catalanismes al grec medieval
}

\section{Catalanisms in Medieval Greek}

\author{
Sandra Pérez Ródenas \\ Universitat de València \\ sanpero6@alumni.uv.es
}

Data de recepció: 14/04/2018

Data d'aceptació: 10/07/2018

\section{Resum}

La relació entre dues llengües com són el grec i el català no ha estat pràcticament estudiada. Tan sols podem esmentar els esforços de Joan Coromines i de l'hel·lenista Jordi Redondo. Sabem que la llengua catalana posseeix hel·lenismes que s'introduïren a diverses èpoques i per diverses raons. Tot i això, mai s'havia proposat un contacte directe entre ambdues llengües. No obstant això, molts són els motius històrics i lingüístics per pensar que hi va haver un contacte directe català-grec, el qual podria explicar tant els manlleus grecs que trobem al català, com els catalanismes que trobem al grec medieval. Els materials dels quals disposem per a demostrar aquesta hipòtesi són limitats. Tanmateix, sí que trobem a textos grecs medievals alguns catalanismes, la major part dels quals pertanyen al camp semàntic de la marineria. Així, sembla més possible pensar que certament existís una situació de bilingüisme que justificar aquestos manlleus prenent una llengua franca com a intermediària.

Paraules clau: català medieval; grec medieval; bilingüisme; catalanismes; manlleus.

\begin{abstract}
The relationship between two languages as Greek and Catalan has not practically been studied. It can only be mentioned Joan Coromines' efforts as well as those of the Hellenist Jordi Redondo. It is known that Catalan language possesses Hellenisms introduced in different ages and for different reasons. Nevertheless, a direct contact between both languages had never been proposed. However, there are many historic and linguistic reasons for thinking that there was a direct contact between Greek and Catalan, which could explain both, the Greek loanwords which can be found in Catalan and the catalanisms found in Medieval Greek. The means for demonstrating this hypothesis are limited. Nonetheless, some catalanisms can be found in Medieval Greek texts, most of them belonging to the seamanship's semantic field. Therefore, it seems more accurate to think that certainly there was a situation of bilingualism rather than to justify these loanwords for the sake of a lingua franca's intermediation.
\end{abstract}

Keywords: Medieval Catalan; Medieval Greek; bilingualism; catalanisms; loanwords. 



\section{Taula de continguts}

1. Introducció: la relació entre el grec i el català

2. Exemples d'hel·lenismes al català medieval

3. Hipòtesi d'un contacte directe entre grec i català medievals

4. Exemples de catalanismes al grec medieval

4.1. Catalanismes pertanyents al camp semàntic de la marineria

4.2. Catalanismes pertanyents al camp semàntic de la vida diària

5. Conclusions

Bibliografia 



\section{Introducció}

La relació entre dues llengües mediterrànies com són el grec i el català no ha estat força estudiada, sols podem esmentar els esforços de Joan Coromines al seu Diccionari Etimològic $i$ Complementari de la Llengua Catalana (1980-1991) i l'article de l'hel·lenista Jordi Redondo, titulat «Hel·lenismes al català medieval: Bilingüisme o llengua franca?» (1999), a partir del qual ha sorgit aquesta investigació.

Partim del fet que al català, com succeeix a les altres llengües romàniques, trobem un gran nombre d'hel·lenismes que hi penetraren a diverses èpoques (Nadal i Prats, 1982: 26).

1. Per intermediació del llatí. Trobem sobretot paraules de caire religiós com ara àngel

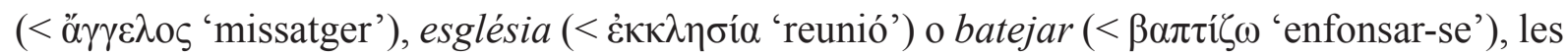
quals han sofert un desplaçament semàntic basat en la metàfora (id est: 'l'àngel' és l'encarregat de difondre el missatge diví). Ara bé, no hem de perdre de vista l'advertència que ens fan Montserrat Ros i Joan Alberich a la introducció del seu llibre La transcripció dels noms propis grecs i llatins (1993): tot i que la tendència general, tant al català com a la resta de les llengües de la Romània, siga que els hel·lenismes penetren a la llengua en un primer moment per intermediació del llatí, açò no sempre succeeix seguint aquest ordre, ja que els hel·lenismes també poden introduir-se directament a les llengües romàniques, sense necessitat de que el llatí actuï com a intermediari.

2. A època bizantina. Novament trobem exemples de paraules de semàntica religiosa, per

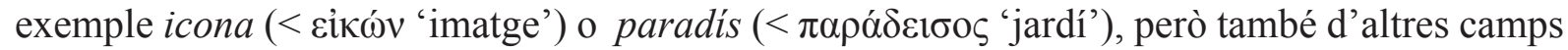

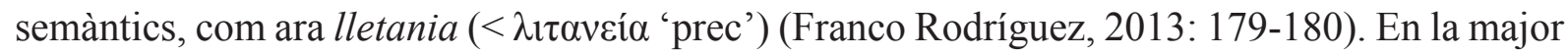
part dels casos, aquestos hel·lenismes d'època bizantina penetraren al català per intermediació del llatí. No obstant això, cal que en aquest punt considerem un fet històric: el domini bizantí al territori català es va estendre durant molts segles, especialment en el cas de ses Illes, on aquesta ocupació va començar al voltant del 534 i va perdurar fins l'any 903. Aleshores, tot i que no trobem un gran nombre d'exemples de bizantinismes al català, ens sembla factible afirmar que aquestos vora 400 anys d'ocupació necessàriament deixarien una empremta a nivell lingüístic. Alguns exemples d'hel·lenismes al català (concretament al català de ses Illes) que considerem que 
penetraren durant aquest període del domini bizantí són dos ictiònims, palomida $(<\pi \alpha \lambda \alpha \mu i ́ \delta \alpha)$ i esparrall $(<\sigma \pi \alpha ́ \rho \rho \varsigma)$.

3. A l'Edat Mitjana, generalment, per intermediació de l'àrab. Un exemple molt interessant és el de la paraula alfòndec (cf. castellà alhóndiga; italià fondaco; venecià fontego). Coromines (1980-1991: 186-187 s.v. alfòndec) informa de que aquest mot prové de l'àrab fúnduq ('hostal on s'allotjaven els mercaders amb llurs mercaderies'), el qual procedeix del grec $\pi \alpha v \delta$ o $\chi \varepsilon \tilde{i} v^{1}$ ('fonda', literalment 'lloc on reben tothom'), amb una fricativització de l'oclusiva bilabial sorda $/ \mathrm{p} /$, ja que aquest fonema no existeix a l'àrab. A més, cal afegir que al català trobem una forma amb article, alfòndec, malgrat la tendència general del català a suprimir l'article (per exemple, a partir de l'àrab súkkar trobem en castellà una forma amb article assimilat, azúcar -al-sukr >as-sukr-, front a la forma sense article del català, sucre).

4. Entre els segles XIII-XV, etapa en la qual hem centrat aquesta investigació i que ha estat parcialment estudiada pel professor Jordi Redondo.

5. A època moderna, per causa del major coneixement del món grec antic i de les innovacions científiques. Trobem neologismes com ara astronauta, hemorràgia, paleologia...

\section{Exemples d'hel·lenismes al català medieval}

Partim de la base que al català -i a la resta de llengües romàniques-, com acabem d'exposar, trobem un gran nombre d'hel·lenismes. Això ens porta a reflexionar sobre si també succeeix el fenomen invers: existeixen també catalanismes al grec? Tornarem a aquesta pregunta, que té una resposta afirmativa, més endavant. Comentarem, però, alguns exemples d'aquestos hel·lenismes al català que trobem a la literatura catalana del s. XIV.

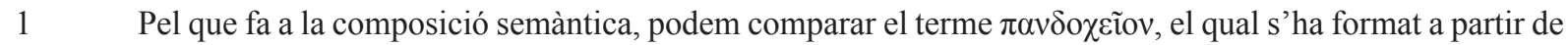

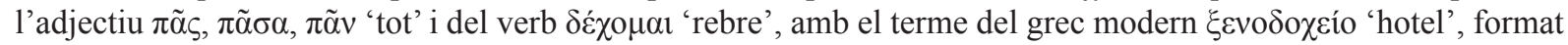

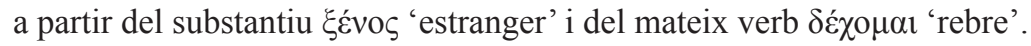


El professor Redondo ha dedicat dues obres a l'estudi dels hel·lenismes a la Crònica de Muntaner (2000 i 2016, aquesta segona amb la col·laboració dels professors Kioridis, Ferrer i Pomer) i conclou que trobem fins a nou hel·lenismes a l'obra de Muntaner, tots ells substantius. Per exemple:

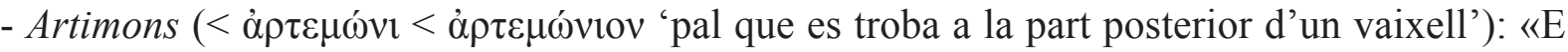
ell, ab la sua galera primera, pensà d'entrar ab los artimons bords que hi havia ferrats» (Olwer, 1926: 13).

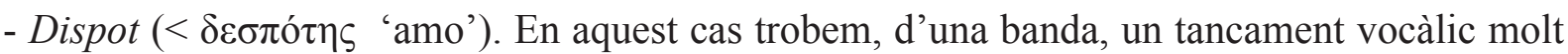
habitual a les evolucions fonètiques, i d'altra banda, la supressió de la desinència del nominatiu $-\eta \varsigma$ : «E con fo al ducat, lo dispot de l'Arca desafià-lo» (Olwer, 1926: 106).

Podem posar aquest terme en relació amb una paraula que trobem a l'obra d'Eiximenis, lipot, terme del qual es desconeixia el significat fins que Ayensa i Prat (1999-2000: 377-382) proposà, des del nostre punt de vista, molt encertadament, que es tracta del resultat de l'article i del substantiu del grec medieval i $\pi \pi$ ó $\eta \zeta$, que es correspondria amb el terme del grec antic i $\pi \pi \varepsilon v ́ \varsigma$ 'genet'. En els dos casos, dispot i lipot trobem la supressió de la desinència del nominatiu masculí singular, - $\eta \varsigma$.

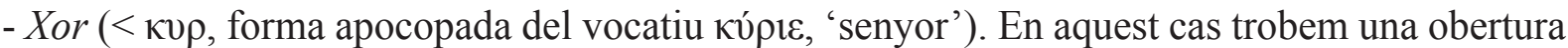
vocàlica, fenomen molt habitual a les evolucions fonètiques, i, d'altra banda, una palatalització de la velar sorda pròpia de la zona de Capadòcia. A mena de curiositat, podem dir que fins i tot a dia d'avui, al grec modern trobem aquesta palatalització a la zona del nord de Grècia i a Creta: «E la galea anà tant, que en poc de temps fo en Constantinoble, on trobà l'Emperador xor Andronico e son fill major xor Miqueli» (Olwer, 1926: 20).

- Lleny, amb el significat de 'vaixell'. Aquest no és un exemple d'un hel·lenisme lèxic, sinó semàntic. En grec, el terme $\xi u ́ \lambda o v$ significa 'tronc d'un arbre', però per metonímia passa a designar a tot l'arbre, i, novament per metonímia, qualsevol objecte fet amb fusta: «(...) gran nau de tres cubertes quel rey Carles trametia a Cathania, e marinala, e 
tramesla a Macina, e dona gran larguea a la ciutat ab les altres naus e lenys» (Kioridis, Ferrer, Pomer i Redondo, 2016: 10).

Però no sols trobem hel·lenismes a aquesta obra. El professor Redondo (2013a) també ha estudiat l'obra anònima del s. XIV anomenada Història de Jacob Xalabín, on també ha sigut possible localitzar hel·lenismes, com ara mandil ( $<\mu \alpha v \tau \eta ́ \lambda \imath$ 'mocador') o quir, terme que, com l'abans esmentat xor, procedeix d'una forma apocopada del vocatiu кúpıє 'senyor'.

Una altra obra que necessariament hem d'esmentar és L'Espill de Jaume Roig, composada al voltant del 1460. Redondo (2013b) dedicà un estudi a les fonts d'aquesta obra, sense deixar d'incloure al seu treball alguns comentaris de caire lingüístic. Redondo (2013b: 204-205) destaca la presència del substantiu cantarida a l'obra de Roig:

\begin{abstract}
Per llurs usances / així diverses / e tan perverses / obres e manyes, / són alimanyes; / serp tortuosa / són e rabosa, / mona, gineta, / talp, oroneta, / mussol, putput, / gall, cutibut, / aranya amb tela, / tavà, mustela, / vespa, alacrà, / rabiós cà, / la sangonera / e vermenera, / mosca e grill, / llebre, conill, / drac calcatrís, / tir basalís, / vibra parida / e cantarida, / onsa parda / e lleoparda, / lloba, lleona, / la escurçona. / Són llop de mar, / lo peix mular, / drac e balena, / polp e serena, / de milà coa. / A qui la lloa / de llur bellea, / més de noblea, / són bellmarí; / de llur verí / oir no’ls plau. / Si n'escoltau / qualsevol d'elles / dir maravelles / e grans llaors / del llur bell cors, / no's farta mai: / com papagai, / de llengua juga; / diu-se tartuga / (jamai ofèn, / res no despèn / ni beu ni tasta); / com tortra casta, / en verd no's posa; / com pariposa, / de l'aire viu; / vetlant se diu / grua, gall, oca, / curosa lloca, / cadell' amiga, / sirgant formiga, / simpla coloma, / llisa de ploma / e sense fel (Carré, 2001, llibre III, vv. 1320-1381).
\end{abstract}

Carré (2006: 816) explica al seu glossari que aquesta paraula és, evidentment, plana i que significa 'insecte coleòpter'. Aleshores, en aquest passatge en què la dona és comparada amb una sèrie d'animals, trobem la comparació amb aquest insecte. Els biòlegs recullen aquest terme propi de l'entomologia, que es correspon amb el català escarabat, l'occità escarabat, l'aragonès escaracho, el francès scarabée, el castellà escarabajo i el portuguès escaravelho (Redondo, 2013b: 204)². L'occità, a més, testimonia un terme cantarida i un fitònim cantaridièr-el freixe-, però es tracta, en paraules de Redondo (2013b: 204), 'd'un miratge etimològic, perquè se'l fa derivar del llatí cantharis, -idis, talment com fa Coromines (1980-1992: 486 s.v. cantàrida) per al terme català'.

$2 \mathrm{Al}$ costat d'aquesta arrel es documenten solucions com la de l'italià bostrico i el portuguès bosteiro (Redondo, 2013b: 204). 
Ara bé cantharis, -idis no és un terme pròpiament llatí, sinó que és un neologisme creat per Linnaeus a mitjan s. XVIII. És a dir, Linnaeus va adoptar un terme habitual a la llengua grega a partir de certa època en la qual l'antic substantiu masculí кóv $\theta \alpha \rho \varsigma_{\varsigma}$ 'escarabat' -d'etimologia imprecisa $^{3}$ - fou reemplaçat per la forma femenina $\kappa \alpha v \theta \alpha \rho i ́ \varsigma$, que s'aplica també com a ictiònim i com a fitònim (Gil, 1959: 226-228). En resum: no trobem a cap llengua romànica derivats del tipus cantarida, l'ús del qual es limita a la llengua tècnica de l'entomologia (Redondo, 2013b: 204). Si es troba a algunes parles de l'italià meridional, es tracta indiscutiblement d'un préstec de la llengua grega pròpia d'aquestos territoris segles abans de l'expansió del llatí (Redondo, 2013b: 205).

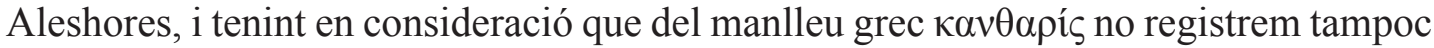
cap signe mínim de vitalitat al català, considerem que la única alternativa possible és la d'explicar l'aparició d'aquest terme com un cas d'hel·lenisme de traducció (Redondo, 2013b: 205). De fet, el professor Redondo (2009: 148) ja havia identificat al text de Roig altres manlleus del grec medieval ben significatius. Per què es consideren aquestos manlleus significatius? Per moltes raons: 'tant perquè en alguns casos es tracta de termes no tècnics, com perquè arreu més no els registrem, al llarg de tota la història de la llengua catalana. No es tracta, doncs, a dreta llei, de manlleus, sinó de les evidències d'un anostrament imperfecte, un dels responsables del qual entenia els termes grecs en qüestió i era més competent en aquesta llengua que no en la catalana'.

El cas de la 'sirgant formiga' mereix un últim comentari sobre els hel·lenismes presents

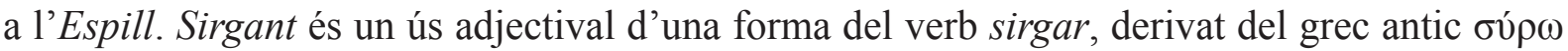
( $\sigma \varepsilon ́ p v \omega$ en grec modern) 'arrossegar' (Redondo, 2013b: 206). Tot i les objeccions de Coromines (1980-199: 938-942 s.v. sirga) a reconèixer sirga i sirgar com a manlleus del grec medieval, considerem que per l'àmbit d'ús s'ha d'incloure dins dels nombrosos préstecs derivats del contacte entre grecs i catalans a la Baixa Edat Mitjana (Redondo, 2013b: 206).

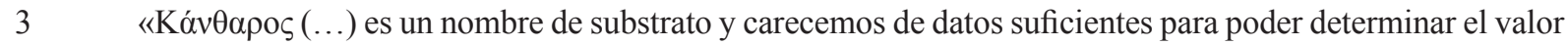
semántico del sufijo - $\alpha \rho$-» (Gil, 1959: 227). 


\section{Hipòtesi d'un contacte directe entre grec i català medievals}

Aleshores, malgrat que, com hem pogut comprovar, existeixen molts hel·lenismes a la llengua catalana, mai no s'ha considerat que existís un contacte directe entre ambdues llengües. No obstant això, proposem que efectivament va existir una situació de bilingüisme, o almenys de contacte directe català-grec durant els s. XIII-XV per diversos motius (Redondo, 1999: 175-176):

1.- Existeixen manlleus grecs al català medieval i catalans al grec medieval.

2.- No sembla que aquestos manlleus es deguin a la intermediació d'una llengua franca.

3.- Aquestos manlleus no refereixen a un únic camp semàntic.

L'escassetat documental és un problema a l'hora de seguir aquesta investigació. Sols podem recol·lectar dades a partir de documents històrics. Ara bé, també existeixen raons històriques que donen suport a la nostra hipòtesi (Redondo, 1999: 176-178).

1. Ens situem en un context històric en el qual existí una hegemonia catalana al món mediterrani. El domini català a l'Àtica i a la Grècia central (la coneguda entre els grecs com la Catalanocràcia) va ser breu (1311-1394), però, tot i aquesta brevetat, els catalans introduïren a Grècia costums polítics i comercials propis. Especialment significatiu fou el comerç marítim i les relacions comercials entre grecs i catalans, de fet, la majoria dels catalanismes al grec medieval, com veurem a continuació, pertanyen al camp semàntic de la marineria. A més, és especialment interessant aquest punt ja que sabem que principalment es comercialitzava amb esclaus grecs, els quals arribaven als ports de les Illes Balears, de Catalunya i del País Valencià. Per què diem que és especialment interessant aquest punt? Perquè aquest fet ens indueix a pensar en quina seria la relació d'aquestos esclaus grecs amb els seus amos: en quina llengua parlarien? En el cas que hi haguessin també dones esclaves, aquestes es casarien amb els seus amos?

2. L'arribada de les tropes dels almogàvers a Grècia (s. XIV) provocà que unes 200 famílies catalanoparlants s'instal·laren a la que era la capital del comtat, a Tebes. A banda, sabem 
de l'existència d'un funcionariat grec que coneixia perfectament el català, fet que implica que van haver-hi diverses generacions bilingües de grec i català (Ayensa i Prat, 1999-2000: 378).

3. Al domini català corresponen també, no només una profunda admiració per l'hel·lenisme, sinó també una època de floriment d'Atenes, que havia estat força oblidada durant llargs segles, i que a partir del s. XIV tornà a donar mostres de vitalitat. Per exemple, el 1337 el copista Dimitris Perulis s’ocupà de les obres d’Hesíode, Píndar i Teòcrit (Redondo, 1999: 178).

\section{Exemples de catalanismes al grec medieval}

Una vegada exposades les raons per les quals ens sembla versemblant la hipòtesi que existí un contacte directe grec-català entre els segles XIII-XV, procedim a citar alguns exemples que recull el professor Redondo (1999) de catalanismes al grec medieval.

\subsection{Catalanismes pertanyents al camp semàntic de la marineria}

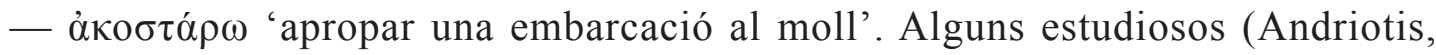
1951/1992: 11) proposen que es tracta d'un italianisme. Coromines (1980-1991: 1000 s.v. acostar), no obstant això, proposa que aquest verb procedisca del català acostar ja que no hi ha cap paral·lel d'aquest verb a altres llengües romàniques fora de l'occità, el castellà i el francès.

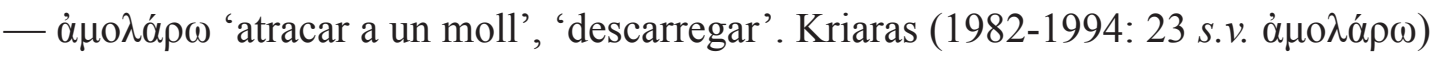
i Andriotis (1951/1992: 16) posen aquest verb en relació amb el substantiu italià molo 'mol' i amb un hipotètic verb *mollare o *amollare. Coromines (1980-1991: 748 s.v. amollar), d'una manera molt encertada, refuta aquesta etimologia i considera que aquest verb grec procedeix del verb català amollar, ja que sembla molt més possible que provinga directament d'un verb i no pas d'un nom.

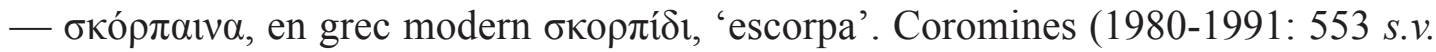
escorpa) considera que aquest ictiònim és un catalanisme ja que apareix documentat per primera 
vegada a un document de Mallorca de l'any 1361. Ovidi Carbonell (2010: 38) recolza aquest origen del terme 'escorpa' i analitza l'etimologia d'altres ictiònims a un estudi de l'any 2010.

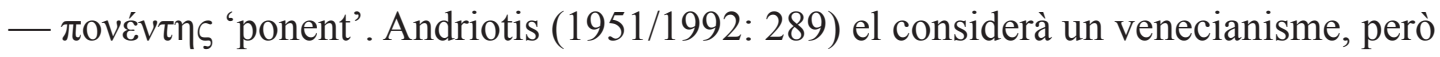
el seu ús és tan limitat a la marineria italiana, i és tan emprat, però, a la marineria catalana que tot fa pensar que efectivament es tracta d'un catalanisme (Redondo, 1999: 183)

\subsection{Catalanismes pertanyents al camp semàntic de la vida diària}

— $\alpha \rho \delta \varepsilon \rho i ́ v \alpha$ 'cadernera'. Aquest és un terme exclusiu del català, l'occità i l'aragonès -on trobem la forma cardelina. També al català de Mallorca trobem l'arcaisme caderlina (Coromines, 1980-1991: 387 s.v. cadernera). Cal afegir que les oscil·lacions entre la líquida lateral i la líquida vibrant són força habituals a moltes llengües.

— $\mu \pi \alpha \rho \alpha ́ \kappa \alpha$ 'barraca'. Kriaras (1982-1994: 100 s.v. $\mu \pi \alpha \rho \alpha ́ \kappa \alpha)$ i Andriotis (1951/1992: 263) indexen aquest terme com a venecianisme. Hi ha raons cronològiques que ens permeten negar aquesta procedència (Coromines, 1980-1991: 667-672 s.v. escorpa): aquest terme s'enregistra al grec per primera vegada al s. XVI. El testimoni més antic d'aquesta paraula el trobem a un text valencià que data del 1249. En canvi, no el trobem a l'italià fins als segles XVII-XVIII.

- $\mu \pi$ ov $\gamma \alpha \dot{\delta} \alpha$ 'bugada'. Considerem que es tracta d'un catalanisme pel que fa al vocalisme (cf. sard bogada; calabrès vucata) i no pas d'un venecianisme, com sosté Andriotis (1951/1992: 222), ja que a l'italià trobem la forma bucato, amb una terminació en $-o$ front a la forma catalana acabada en $-a$.

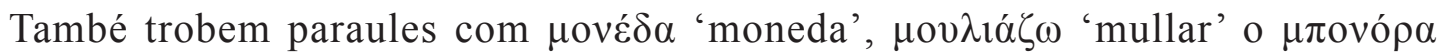
'bonhora'que, tot i que podrien ser italianismes, res no fa pensar que no puguen ser catalanismes, no sols per la transparència etimològica, sinó també pel seu ús més que habitual al català (Redondo, 1999: 184).

En últim lloc, esmentarem també que, durant els últims anys de l'Imperi Bizantí, s'intensificaren les relacions entre els grecs i els seus invasors francs (Ayensa i Prat, 1997: 43). 
Per això, molts filòlegs i estudiosos de la literatura han dedicat els seus esforços a buscar un origen romànic a moltes novel·les de cavalleria gregues. En canvi, no s'han dedicat tants esforços a l'estudi de la poesia popular, tot i que sens dubte, la cançonística comparada de les balades gregues i les cançons populars mediterrànies seria una tasca molt interessant i reveladora. En aquesta línia d'investigació s'inscriu l'article d'Ayensa i Prat (1997), qui investigà un possible origen grec de la balada catalana anomenada La dama d'Aragó. L'erudit oxoniense William J. Entwistle (1938) fou el primer a adonar-se'n de les semblances entre aquesta cançó catalana i la balada grega titulada La padrina convertida en núvia.

Menció a banda mereix el cas de la llegenda de l'heroi Sant Jordi. El motiu de l'heroi que dóna mort a un drac o monstre que tiranitza un poble exigint una donzella com a tribut està ben testimoniat al folklore d'arreu del món (Ayensa i Prat, 2000: 276). En el cas de la Grècia Antiga, els mites de Cadme o Peseu són un clar exemple de que aquest tema arriba, mitjançant les fonts bizantines, fins l'actualitat. Ara bé, Ayensa i Prat (2000: 276) assenyala que un dels majors problemes relatius a l'estudi de la llegenda de Sant Jordi és la seua relació amb la tradició cristiana: el testimoni de Joan de Damasc (segles VII-VIII), clarament contrari a les creences de l'existència de dracs i d'altres monstres de la imaginació popular, conclou que l'església, incapaç d'eradicar aquestes creences paganes, acabà assimilant-les i incorporant-les a les hagiografies. En qualsevol cas, la llegenda de Sant Jordi, amb aquesta barreja d'elements cristians (exaltació de Sant Jordi) i pagans (l'existència de sers de natura monstruosa) arrelà al poble grec (Ayensa i Prat, 2000: 276). Possiblement aquesta llegenda tingué origen a l'Àsia Menor, pàtria tradicional dels dracs, on trobem també un gran nombre de versions de contes que circularen per tota Grècia i que versen sobre aquesta temàtica, proba irrefutable de l'antiguitat de la mateixa (Ayensa i Prat, 2000: 276). A mena de curiositat, afegim que encara avui dia es celebra a algunes regions gregues, com ara l'Arcàdia, Tessalònica, Beòcia o Tràcia, la victòria de Sant Jordi sobre el drac el dia 23 d'abril.

El cas invers és el que trobem en la Història de Pere i Margarona, un poema grec que, segons la crítica (Schreiner, 1930: 121-130), fou compost directament a partir de l'original català, el qual hauria circulat per Grècia al s. XIII. Es considera que aquest poema grec procedeix 
directament de la versió original catalana perquè presenta notables diferències enfront la versió francesa. Constatem, d'aquesta manera, la necessitat d'aplicar les premisses de la literatura comparada al cas de la poesia popular grega, i convidem els estudiosos a centrar-se en aquest

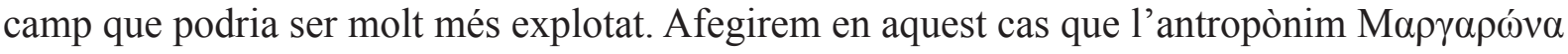

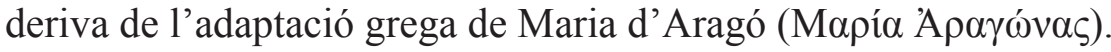

\section{Conclusions}

Després de tots els exemples esmentats, ens oposem a la teoria de l'existència d'una llengua franca mediterrània que justificaria la presència de manlleus a diverses llengües mediterrànies, teoria que sostenen estudiosos com ara Bryer (1973) o Bádenas (1995).

Davant aquesta hipòtesi, proposem que existeixen raons històriques, polítiques i lingüístiques suficients que fan pensar que existí una situació de bilingüisme, o almenys de contacte directe, entre el grec i el català entre els segles XIII-XV. Aquestos manlleus presents en ambdues llengües no es deurien, aleshores, a la intermediació de cap llengua franca.

Sostenim aquest parer ja que:

1. Els manlleus són bidireccionals (trobem catalanismes al grec medieval i també hel·lenismes al català medieval).

2. El context històric demostra que hi hagué una interrelació entre grecs i catalans a aquest període, afavorida pel comerç marítim, centrat bàsicament en el comerç d'esclaus. El fet que principalment es comercialitzés amb esclaus no deu perdre's de vista ja que aquestos esclaus grecs es relacionarien amb els seus amos catalans.

3. Els manlleus catalans al grec medieval que hem esmentat no pertanyen a un únic camp semàntic, si bé és cert que la majoria d'aquestos formen part del camp semàntic de la marineria.

4. A altres llengües de la zona balcànica també trobem catalanismes. Per exemple, els mots amolar, bugada i moneda també existeixen al vàlac, la llengua dels aromanesos de Bulgària 


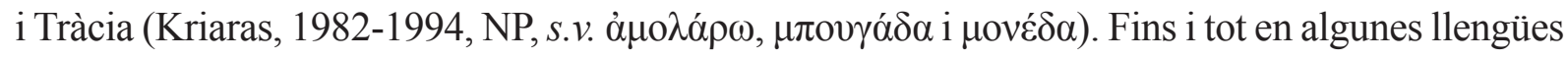
eslaves trobem mots que podrien respondre a catalanismes, per exemple, trobem el terme монета 'moneda' al serbocroat. Més interessant és el fet que també trobem catalanismes al turc, tal i com ens ha sigut possible comprovar després de l'estudi del professor Redondo (2012) sobre els

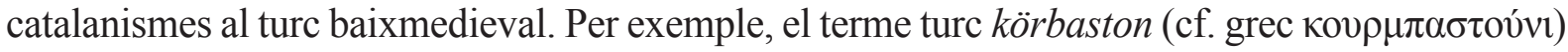
procedeix del nom català corbató 'peça de fusta orbada que serveix per a subjectar o reforçar la unió de dues peces que formen angle' (Redondo, 2012: 323).

En conclusió, tot i que sembla factible pensar que existí un contacte directe entre aquestes dues llengües, cal tenir especial precaució ja que les dades de què disposem són escasses. Nosaltres com a hel·lenistes hem tractat d'aplicar els nostres coneixements per a aportar un poc de llum a una qüestió tan obscura com és l'origen de certs manlleus a les llengües mediterrànies a època medieval. Convidem, aleshores, els estudiosos d'altres disciplines, com ara del turc o de les llengües eslaves, a analitzar manlleus d'aquest mateix període i contrastar resultats per a un millor coneixement de la llengua a aquest estadi sincrònic. 


\section{Bibliografia}

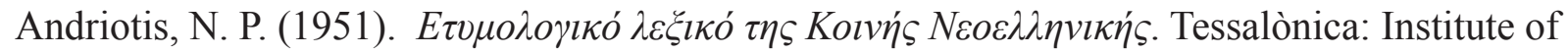
Modern Greek Studies, Foundation Triandaphyllidis, 1992.

Ayensa i Prat, E. (1997). «Sobre l'origen grec de La dama d'Aragó», en J. Mas i Vives (Ed.), Actes de l'Onzè Col·loqui Internacional de Llengua i Literatura Catalanes, Volum 3, pp. 43-69. Barcelona: Abadia de Montserrat.

Ayensa i Prat, E. (1999-2000). «Lipot: un préstec grec en 1'obra de Francesc Eiximenis», en Boletín de la Real Academia de Buenas Letras de Barcelona, Volum 47, pp. 377-382.

Ayensa i Prat, E. (2000). Baladas griegas. Estudio formal, temático y comparativo. Madrid: Consejo Superior de Investigaciones Científicas.

Bádenas, P. (1995). «La lingua franca, moyen d'échange et de rencontre dans un milieu commun», en Byzantinoslavica, Volum 56, pp. 493-505.

Bryer, A. (1973). Cultural Relations Between East and West in the Twelfth Century. en D. Baker (Ed.), Relations Between East and West in the Middle Ages, pp. 77-94. Edimburg: Transactions Publishers.

Carbonell, O. (2010). «Sobre l'etimologia de golfàs», en La Rella, Volum 23, pp. 35-40.

Carré, A. (Ed.) (2001). Spill. Jaume Roig. Alacant: Biblioteca Virtual Joan Lluís Vives.

Carré, A. (Ed.) (2006). Jaume Roig. Espill. Barcelona: Quaderns Crema.

Coromines, J. (1980-1991). Diccionari Etimològic i Complementari de la Llengua Catalana. Barcelona: Curial.

Entwistle, W. J. (1938). «La dama de Aragón», en Hispanic Review, Volum 6, pp. 185-192.

Franco Rodríguez, J. R. (2013). Los étimos griegos en los diccionarios etimológicos de los siglos XVI y XVII. Tesis Doctoral, Universidad Complutense de Madrid. 
Gil, L. (1959). Nombres de insectos en griego antiguo. Madrid: CSIC.

Kioridis, I.; Ferrer, E.; Pomer, J. J. i Redondo, J. (2016). Ramon Muntaner. La secció grega de la Crònica. València: Rhemata.

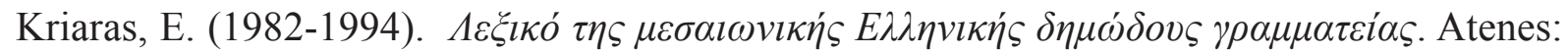
National Hellenic Research Foundation.

Nadal, J. i Prats, M. (1982). Història de la llengua catalana I. Dels orígens al s. XV. Barcelona: Edicions 62.

Redondo, J. (1999). «Hel·lenismes al català medieval: Bilingüisme o llengua franca?», en Quaderns de filologia de la Universitat de València Estudis Lingüistics, Volum 4, pp. 173-186.

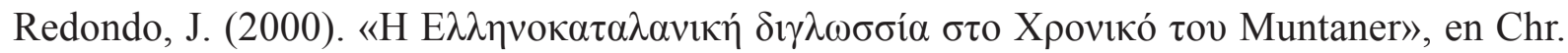

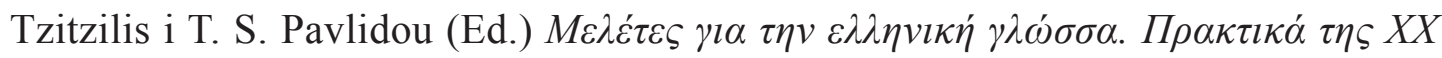

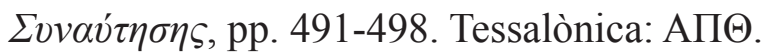

Redondo, J. (2009). «L'Espill de Jaume Roig i la poesia satírica bizantina», en L. Pomer, J. Redondo, J. Sanchis Llopis i J. L. Teodoro (Ed.) Les literatures antigues a les literatures medievals, pp. 123-148. Amsterdam: A. M. Hakkert Publishing.

Redondo, J. (2012). «Sobre catalanismes al turc baixmedieval», en Zeitschrift für Katalanistik, Volum 25, pp. 321-336.

Redondo, J. (2013a). «El gènere i les fonts de la Història de Jacob Xalabín», en eHumanista, Volum 25, pp. 276-314.

Redondo, J. (2013b). «Observacions sobre les fonts de l'Espill de Jaume Roig», en J. J. Pomer, J. Redondo i R. Torné (Ed.) Misogínia, religió i pensament a la literatura del món antic i la seua recepció, pp. 185-212. Amsterdam: A. M. Hakkert Publishing. 
Ros, M. i Alberich, J. (1993). La transcripció dels noms propis grecs i llatins. Barcelona: Enciclopèdia Catalana.

Schreiner, H. (1930). «Neue Quellen zur Komposition und Entstehungsgeschichte des mittelgriechischen Romans Imberios und Margarona», en Byzantinische Zeitschrift, Volum 30, pp. 121-130.

Olwer, N. (Ed.) (1926). R. Muntaner. L'expedició dels catalans a Orient, abstracte de la Crònica. Barcelona: Barcino. 